
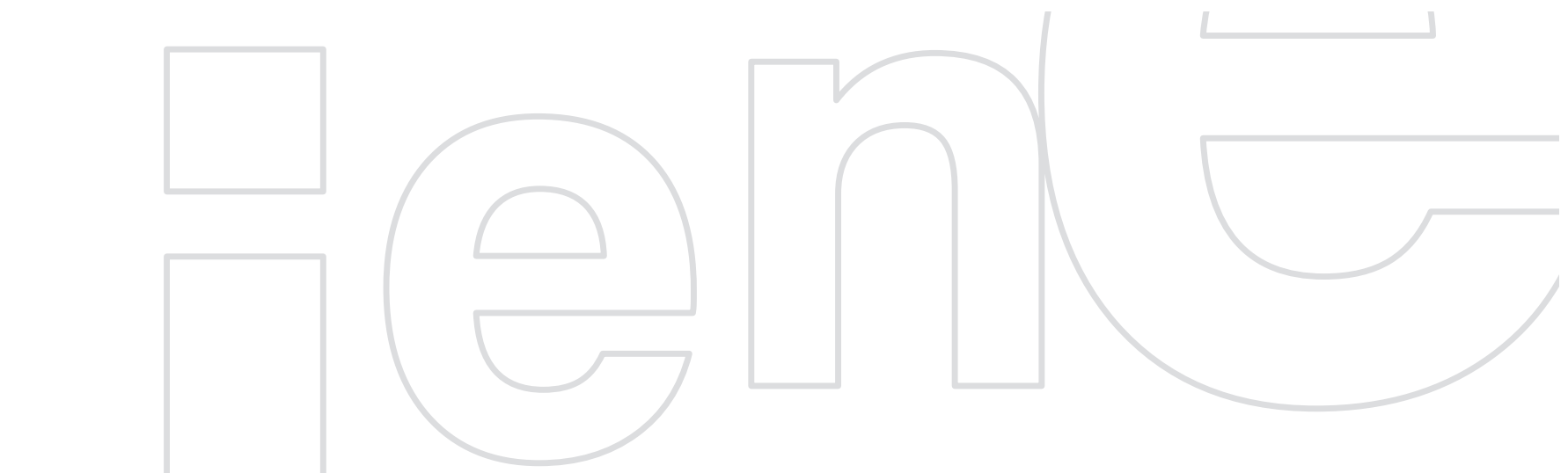

\title{
Resenhas
}

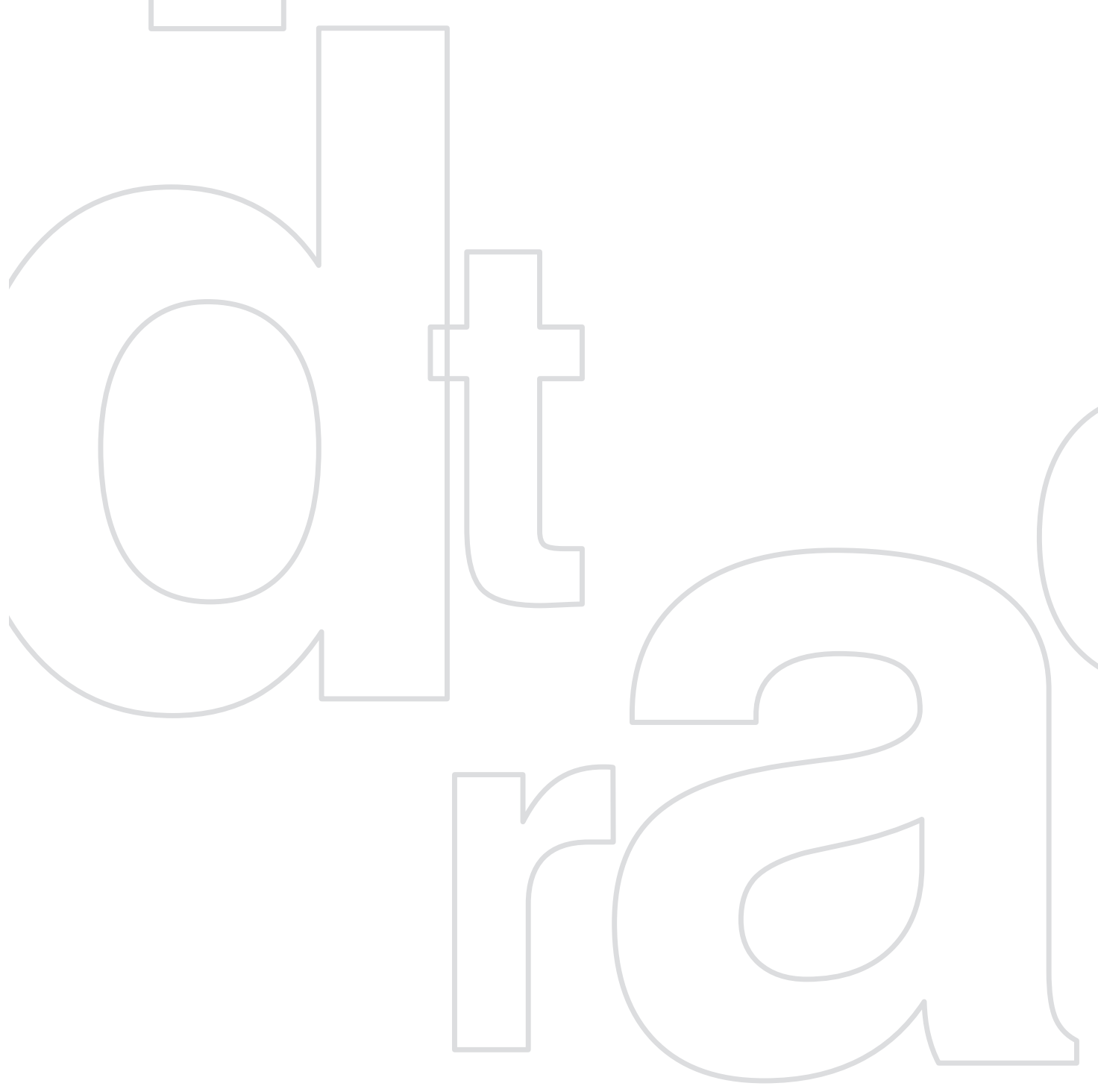




\section{MARSICO, G.; KOMATSU, K.; IANNACCONE, \\ A. Crossing boundaries: intercontextual dynamics between family and school. Charlotte, NC: Information Age Publishing,}

2013.

Crossing Boundaries: Intercontextual Dynamics Between Family and School é uma coletânea publicada em 2013 pela Information Age Publishing (IAP), organizada por Giuseppina Marsico (Universidade de Salerno), Koji Komatsu (Universidade Osaka Kyoiku) e Antonio Iannaccone (Universidade de Neuchâtel). O livro está organizado em duas seções, com cinco capítulos (1-5) na primeira seção e seis capítulos (6-11) na segunda. A primeira seção é intitulada Explorations of Regulatory Dynamics Taking Place During the Encounters of the Two Microsystems e a segunda Analyses of the Representations' System Produced by the Actors in One Context (Family) Towards the Other Microsystem (School). Na última seção estão inseridos, ainda, três capítulos finais (Commentary; General Conclusion: Moving Between the Social Spaces: Conditions for Boundaries Crossing; e About the contributor).

A coletânea representa uma aproximação, um convite para o estudo dos processos educacionais a partir da perspectiva da psicologia cultural. O objetivo central da coletânea é analisar aquilo que acontece na zona de contato (border) entre a cultura familiar e a cultura escolar. O livro apresenta uma discussão sobre as fronteiras existentes entre esses diferentes contextos educacionais. Os autores propõem uma reflexão sobre os variados discursos que surgem na zona de fronteira e sobre o movimento de atravessá-las, observando o que acontece na vida cotidiana dos atores envolvidos. Ao analisarem o movimento entre os espaços sociais e os processos dinâmicos que acompanham o diálogo entre a família e escola, os autores recorrem aos diversos conceitos da psicologia cultural.

A presente resenha refere-se, especificamente, ao capítulo intitulado "Conclusão Geral - Movendo-se entre os espaços sociais: Condições para Atravessar as fronteiras" (General Conclusion: Moving Between the Social Spaces: Conditions for Boundaries Crossing) de autoria de Giuseppina Marsico. Esse capítulo situa-se no final 
da segunda seção do livro, na página 361 e trata do processo de atravessar as fronteiras entre a família e a escola.

Ao observarmos o contexto educacional brasileiro, é possível identificarmos uma fragmentação das vozes da família e da escola sobre o estudante, o que provoca uma separação e um distanciamento que não favorece o diálogo. Uma dificuldade relacionada à criança, ou adolescente, pode estar presente em meio aos dois contextos: o familiar e o escolar. Entretanto, verificamos uma tendência à fragmentação, como se fosse possível realizar tal separação. Muito comumente, a família responsabiliza a escola e a escola responsabiliza a família por situações que expressem alguma crise vivenciada no contexto escolar. Os signos relacionados à culpabilização e à demanda por ações estão presentes tanto na escola e quanto na família, diante da emergência do aluno-problema. Esses signos causam desconforto e costumam transitar de um lado a outro, ora no contexto familiar, ora no contexto escolar. Um aspecto que deve ser considerado nesse processo de (des)responsabilização diante das dificuldades apresentadas pelas crianças e adolecentes parece reverberar na dificuldade de ambos os lados da fronteira em sustentar a lei, o que acaba por delegar ao outro o exercício da mesma. Sendo assim, o diálogo que se estabelece na zona da fronteira, entre esses dois contextos, se apresenta como uma possibilidade cercada de tensão.

A escola brasileira ainda apresenta aspectos que favorecem o distanciamento de um diálogo entre a família e a escola, de uma forma reflexiva e que possibilita o movimento para as intervenções a partir das demandas e produções singulares do aluno. De modo geral, a escola se posiciona em um lugar assimétrico em relação à família, ocupando um lugar de poder. Marsico (2013) utiliza a metáfora da varanda (balcony) para indicar o lugar de poder ocupado pela escola. Segundo Marsico, na varanda se faz contato com o externo, há alguma forma de relação com o exterior, mas está presente certo empoderamento sobre o outro. À família, só é permitido o acesso à escola a partir de condições estabelecidas por esta última e, ainda assim, quando ocorre, não se dá de forma integral em virtude dos limites impostos pela mesma. Por mais que permita o acesso e tente proporcionar um diálogo a partir de uma escuta atenta ao que a família expressa, a escola se mantém no lugar assimétrico, que implicitamente envolve, também, uma posição de defesa. 
Porém, tanto no contexto educacional privado quanto no público existem famílias que ultrapassam esses limites, essas fronteiras. No contexto privado, esse movimento pode ocorrer a partir de um signo de consumo, que reconfigura e desafia a assimetria da varanda, visto que reposiciona a família em uma condição de cliente que consome o serviço oferecido pela escola. Esta parece ser uma importante condição que permeia o diálogo entre a escola e a família no contexto privado.

Além disso, o que parece prevalecer é uma preocupação maior com as questões relativas à aprendizagem, considerando que a educação é guiada por fronteiras. Desde macrofonteiras, como os diferentes níveis a serem alcançados na educação formal escolar que revelam uma ideía de acumulação de conhecimento e avaliação de desempenho: do aluno espera-se que assimile o conhecimento proposto, sendo frequentemente avaliado em sua capacidade de apreensão deste conhecimento para em seguida progredir, ou não, para o ano escolar posterior. Essas macrofronteiras já sofreram diversas alterações semânticas ao longo da história recente da educação formal brasileira: o antigo jardim de infância foi renomeado como pré-escola, e agora educação infantil; o ensino primário foi transformado em ensino fundamental e assim por diante. Porém, muito pouco foi alterado no que se refere à lógica de assimilação e avaliação do desepenho acadêmico/escolar pelo estudante. Em outras palavras, mudou-se o semblante, não o conteúdo.

Ainda pensando nessas macrofronteiras, o modelo de progressão linear da educação formal reproduz uma lógica contrária à proposta por Marsico. A educação formal baseada nesta lógica parece privilegiar o desempenho do estudante diante das expectativas criadas pela própria escola ao invés de fomentar as potencialidades deste mesmo estudante.

Tomando-se como referência um grupo de estudantes que estão situados em uma mesma macrofronteira, o sexto ano (antiga quinta série do Ensino Fundamental II) por exemplo, as histórias de vida, crenças pessoais, potencialidades de cada um constituem microfronteiras que são desconsideradas diante da visão homogeneizada desses sujeitos por parte da escola. Quando um aluno apresenta alguma demanda específica, nomeada como queixa escolar, essas microfronteiras são evidenciadas, influenciando no atravessamento das macrofronteiras. Como exemplo, um estudante que apresente conflitos em seu ambiente familiar que reverberam 
(1) Termo criado pelos autores, usado pela primeira vez nesta resenha, para designar um

conjunto de profissionais que têm sido cada vez mais presentes no entorno da escola: psiquiatras, neurologistas, psicólogos, acompanhante terapêutico pediatras e psicopedagogos. em seus relacionamentos com colegas, evidencia que dentro de uma mesma classe há diversos sujeitos singulares (microfonteiras) e que a partir de suas histórias pessoais podem apresentar dificuldades no desempenho escolar e na progressão para a série seguinte (macrofronteiras).

Quando um fenômeno como este ocorre (a queixa escolar) ou quando existe alguma questão, uma "etiqueta" psiquiátrica - Transtorno de Déficit de Atenção e Hiperatividade (TDAH); Transtorno Opositivo Desafiador (TOD); dentre ouros), ou comportamentos que geram incômodo na família ou na escola, o diálogo parece surgir como uma necessidade diante do não saber o que fazer em relaçâo a este quadro. Nestes casos, o diálogo se coloca como "condição" para o desenvolvimento do aluno, e às vezes, até para sua permanência na escola. Se por um lado, esse diálogo pode gerar maior trânsito nas zonas de fronteiras, por outro, é marcado por muitas implicações e resistências. As fronteiras se tornam mais fluidas quando há presença do diálogo, mas ao mesmo tempo surgem dificuldades de falar sobre os assuntos e pensar no que pode ser feito. As zonas de fronteiras se tornam, então, zonas de negociação.

Surge, dessa forma, a demanda real para o atravessamento da fronteira entre a família e a escola. É comum que a família busque ajuda da escola ou procure esclarecer aspectos importantes relacionados às eventuais dificuldades apresentadas pela criança ou adolescente. Do mesmo modo, frequentemente a escola procura a família para solicitar ajuda ou até mesmo encaminhar a criança para outros profissionais como, por exemplo, o parapedagogo: ${ }^{1}$ o médico, o psicólogo, o acompanhamente terapêutico e demais profissionais. Esses profissionais são convocados para responder às demandas de queixa escolar, que, na maioria das vezes, partem dos profissionais da escola ou da família, mas muito raramente dos estudantes.

Marsico desenvolve a ideia de que entre a escola e a família existe um terceiro lugar constituido pela fronteira entre os dois contextos e que emerge diante de situações que exigem o diálogo entre ambos os lados da fronteira. Em circustâncias nas quais a escola e a família são confrontadas a dar respostas sobre uma situação que desconhecem, como nos casos nos quais emerge um aluno-problema, observamos que esse terceiro lugar costumeiramente é ocupado pelos parapedagogos. Esses profissionais (médicos, psicólogos, terapeutas ocupacionais. etc) são convocados 
a responder, descrever e propor soluções para os conflitos que são supostamente o objeto de seu saber. Esses profissionais são, então, convocados a decifrar o enigma que se estabelece quando é identificado um "aluno-problema".

A questão que se coloca é: em que medida esses profissionais que trabalham fora do espaço físico da escola (chamados "parapedagogos", que apresentam consigo seus mais diversos tecnicismos) podem colaborar para a solução dos conflitos que acontecem na escola ou na família? Ao encontrarem uma classificação para os sintomas apresentados pelo estudante, e oferecerem uma etiqueta, não estariam reduzindo o fenômeno e criando marcas que podem afetar o desenvolvimento posterior da criança, ou do adolescente?

Atualmente, percebemos que a escola, no contexto privado, parece demandar e necessitar de outros saberes para responder a tais dificuldades, o que se torna importante na medida em que busca atravessar a fronteira do saber escolar/pedagógico e alcançar o diálogo com as outras áreas para ampliar as possibilidades de intervenção. Por outro lado, a escola parece vivenciar uma angústia do não saber, depositando muitas respostas nesses outros profissionais aos quais recorre, os parapedagogos. A atuação desses profissionais pode marcar a trajetória escolar e desenvolvimental do aluno. Em uma leitura acrítica de suas funções, os parapedagogos podem produzir rótulos, "colar" etiquetas diagnósticas aos alunos, que podem se perpertuar, desresponsabilizando os demais atores envolvidos no fenômeno, como a escola e os pais.

Um dos fundamentos mais caros à psicologia cultural é a concepção da cultura como um processo dinâmico em detrimento da noção de cultura como algo sólido repleto de construções simbólicas imutáveis e na qual o sujeito está inserido em uma relação de objeto, sendo um produto de sua cultura. A escola, ao longo da história, se traduz como uma das instituições que descrevem e representam os valores do tempo e da cultura coletiva. Em sua origem, como ocorreu com outra instituição social, a família, a lei oriunda da lógica patriarcal norteava as relações dentro e fora do contexto escolar. A verticalidade da lei, na modernidade, deu lugar à horizontalidade, na pós-modernidade, tradução da necessidade de reinvenção das soluções como consequência do declínio da autoridade.

Diante disso, podemos entender que a escola ocupava um lugar de saber e de poder. Com as mudanças da pós-modernidade, 
(2) Termo utilizado pelo psicanalista

Charles Melman em seu livro "O

homem sem gravidade", para

se referir a agitação dos corpos

na contemporaneidade em

decorrência do declínio da lei. a escola começa a vivenciar uma crise em relação a tal saber e ao exercício da autoridade. Esta instuição, de modo geral, apresenta uma certa dificuldade e fragilidade nesse exercício, especialmente quando mantém uma relação de clientela com seus estudantes e com suas respectivas famílias Dessa forma, destituida de seu lugar original, fica evidente o apelo que a escola faz à lei (externa). Não se trata de construir juízos de valor quanto a escola atual. A questão parace ser que, em um sociedade horizontalizada, a constituição das fronteiras já é marcada pela diluição, tornando a relação entre escola e família ainda mais tensa diante da falta de lei/autoridade, que gera corpos "sem gravidade", " "presas" fáceis para o discurso dos parapedagogos que diagnosticam e propõem a terapêutica para um sintoma do tempo encarnado no aluno.

Como já exposto, na escola privada o apelo à lei é feito muitas vezes pela via da medicalização. As crianças e adolescentes "problema" são abordadas por parapedagogos como neurologistas, psicólogos, psicopedagogos com o objetivo de reestabelecer a norma no desempenho escolar. No Brasil, diante dos últimos acontecimentos, observamos que na escola pública a questão parece ser da ordem não somente do restabelecimento da norma, mas da lei/ autoridade propriamente dita. Tem aumentado o número de casos em que a polícia é convocada pela escola, e comparece, para dar resoluções a conflitos que antes eram mediados e solucionados no contexto escolar. Como exemplo, recentemente, em uma escola municipal de Salvador- Bahia, a direção da instuição informou às famílias que, na presença de um conflito ou incômodo entre os alunos, os responsáveis deveriam se encaminhar para a delegacia para resolver a situação ou efetuar uma queixa formal. Aqui, já aparece uma questão que marca a vida e o imaginário das crianças e adolescentes: o "sujar" a ficha, o nome diante dos conflitos. Com uma queixa policial, aparece a ameaça da possibilidade do ato ficar registrado como um antecedente criminal, o que, na realidade, se refere à uma situação escolar, que deveria ser resolvida neste contexto e com os envolvidos no conflito.

Em resumo, diante dos argumentos trazidos por Marsico, parece não haver discordância no que se refere à necessidade de atravessar as fronteiras entre a escola e a família, através do estabelecimento de um diálogo que se transforme em uma ponte permanente entre os dois lados da fronteira. No entanto, notamos que essa condição se dá a partir de uma posição institucionalizada. 
O calendário escolar contempla momentos de encontro entre a família e a escola, mas frequentemente esses encontros são caracterizados por um discurso prévio que aborda questões genéricas e que não contempla a singularidade do caso a caso de cada aluno. As reuniões de pais e mestres são o exemplo mais claro desta condição. Nesses casos, o conceito de varanda (balcony), traduz, com precisão, a posição assimétrica da escola com relação à família, pois é a primeira que determina o momento, lugar e a direção desse tipo de evento/encontro. Em contrapartida, na prática, a singularidade do aluno costuma emergir somente quando há o surgimento de uma crise que demanda o atravessamento das fronteiras. No restante dos casos, a singularidade costuma ficar silenciada pela suposta normalidade no desempenho do aluno, que na maioria das vezes o torna invisível à escola.

A pertinência do texto de Marsico reside, principalmente, na possibilidade de uma leitura singular do processo educacional, a partir da constatação de que a fronteira entre a escola e a família, ao fim de tudo, pode ser localizada, corporificada na própria criança ou adolescente. E é a partir dela que se constroem as pontes necessárias entre os lados da fronteira. O aluno seria, então, o terceiro lugar, marcando o "porquê" de atravessar a fronteira e mostrando o "como" esse movimento pode ser feito de forma a contemplar suas particularidades e sua trajetória escolar.

\section{Referência}

MELMAN, Charles. O homem sem gravidade: gozar a qualquer preço. Rio de Janeiro: Companhia de Freud, 2003.

Recebido: 24/09/2013 | Aceito: 24/09/2013 